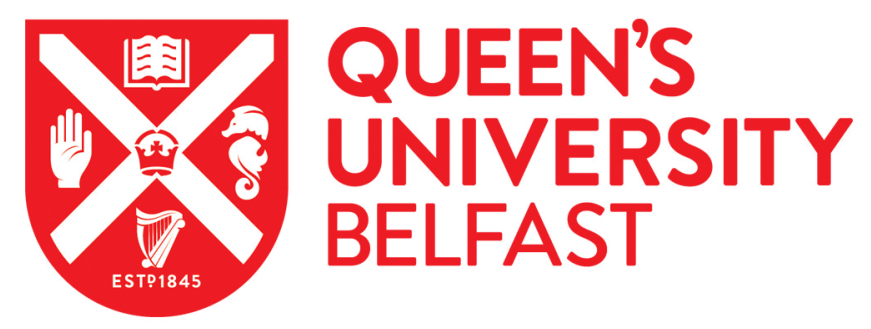

\title{
Exploring and comparing the experience and coping behaviour of men and women with colorectal cancer after chemotherapy treatment $A$ qualitative longitudinal study
}

McCaughan, E., Prue, G., Parahoo, K., Mcllfatrick, S., \& McKenna, H. (2012). Exploring and comparing the experience and coping behaviour of men and women with colorectal cancer after chemotherapy treatment $A$ qualitative longitudinal study. Psycho-oncology, 21(1), 64-71. https://doi.org/10.1002/pon.1871

Published in:

Psycho-oncology

Document Version:

Peer reviewed version

Queen's University Belfast - Research Portal:

Link to publication record in Queen's University Belfast Research Portal

Publisher rights

Copyright 2016 Wiley. This work is made available online in accordance with the publisher's policies. Please refer to any applicable terms of use of the publisher.

\section{General rights}

Copyright for the publications made accessible via the Queen's University Belfast Research Portal is retained by the author(s) and / or other copyright owners and it is a condition of accessing these publications that users recognise and abide by the legal requirements associated with these rights.

Take down policy

The Research Portal is Queen's institutional repository that provides access to Queen's research output. Every effort has been made to ensure that content in the Research Portal does not infringe any person's rights, or applicable UK laws. If you discover content in the

Research Portal that you believe breaches copyright or violates any law, please contact openaccess@qub.ac.uk. 
Exploring and comparing the experience and coping behaviour of men and women with colorectal cancer after chemotherapy treatment: a qualitative longitudinal study.

Short title: The effect of gender on colorectal cancer experience after treatment.

Eilis McCaughan ${ }^{\mathrm{a}}$, Gillian Prue ${ }^{\mathrm{b}}$, Kader Parahoo $^{\mathrm{a}}$, Sonja McIlfatrick ${ }^{\mathrm{c}}$, Hugh McKenna $^{\mathrm{d}}$

${ }^{a}$ Institute of Nursing Research and School of Nursing, University of Ulster, Cromore Road, Coleraine, Northern Ireland BT52 1SA, UK

${ }^{b}$ Institute of Nursing Research, University of Ulster, Shore Road, Newtownabbey, Northern Ireland BT37 OQB, UK

${ }^{c}$ Northern Health and Social Care Trust and University of Ulster, UK

${ }^{d}$ Faculty of Life and Health Sciences, University of Ulster, UK

\section{Address for correspondence:}

Dr Eilis McCaughan

Institute of Nursing Research, University of Ulster, Cromore Road, Coleraine, Northern

Ireland BT52 1SA, UK

Tel: $+44(0) 2870324091$

Fax : $+44(0) 2870324951$

Email: em.mccaughan@ulster.ac.uk

\section{Acknowledgements}

The authors would like to acknowledge the Ulster Cancer Foundation for their financial support.

There are no conflicts of interest to declare. 


\begin{abstract}
Objectives: Men have higher incidence and mortality rates for nearly all cancers. They are less likely than women to utilise cancer information services and other social support services. The aim of this study was to explore and compare the experience and coping behaviour of men and women after treatment for colorectal cancer (CRC).
\end{abstract}

Methods: A longitudinal qualitative study was conducted involving 38 individuals (24 men, 14 women) with CRC. Data were generated using semi-structured interviews at four time points over an 18-month period, post-diagnosis. Interviews focused on participants' experience of $\mathrm{CRC}$ and on how gender affected their coping. This paper reports the findings of interviews three and four which examined the participants' experience after chemotherapy. Results: Three themes emerged from the interviews ('new normal', living with uncertainty and support needs). Many men and women reacted similarly, however there was some variation evident between and within sexes. The main difference was with regards to the long term physical side effects of the illness. Many women admitted to still experiencing side effects whereas many men indicated that they had no problems. These men engaged in practices that aligned with their gender identity and view of masculinity. It must be noted that some men and women were still experiencing an impact.

Conclusions: Recovery from the physical and psychological effects of CRC does not occur simultaneously. Health care professionals should be aware that not all men (or women) conform to the social stereotypes of masculinity (or femininity).

Keywords: cancer, oncology, gender, survivorship, colorectal 


\section{Introduction}

Colorectal cancer (CRC) is the third most common cancer in the United Kingdom and the United States [1,2]. Improvements in survival have been noted over the last 30 years [3]. Individuals with $\mathrm{CRC}$ are the second largest group, after breast cancer, of European cancer survivors [4]. Cancer survivorship has been divided into three stages: the acute stage during diagnosis and treatment, the extended stage which begins on completion of treatment and the permanent stage when the likelihood of cancer recurrence is reduced [5]. Survivors often report lower quality of life than their cancer-free peers [6]. Most research to date has focused on the acute stage of cancer survivorship. It has been recommended that more studies are conducted on individuals on completion of cancer treatment [7].

Although the healthcare needs of people with cancer have been investigated, most studies fail to examine the influence of gender. Traditionally the terms masculinity and femininity have represented a stable set of gender beliefs that distinguish men from women [8]. Gender has been defined as ' $a$ set of socially constructed relationships which are produced and reproduced through peoples actions' [9, 10]. Gender is therefore not something we 'are', but something we 'do' [11]. The widespread assumption of the 'difference' between men and women has been challenged with the idea that there are similarities between, and diversity within, men and women [12]. There are multiple forms of masculinity (and femininity) and therefore variation among men (and women) [13]. Hegemonic masculinity describes men who demonstrate strength, self reliance and limit their emotional responses. This is the idealised form of masculinity $[8,14]$. Although men may endorse similar principles, different men enact these beliefs in different ways $[10,15]$. Women have traditionally been stereotyped as emotional, expressive, compassionate and yielding [11]. It is often assumed (incorrectly) that all men are naturally 'stoical' and choose not to cope through emotional disclosure [16]. Hilton et al [15] warned that we should be wary of stereotyping women as 'expressive' and man as 'stoical'. As explained by Paechter [17] there are many types of masculinity 'inhabited and enacted variously by different people and by the same people at different times'. The same theory could be applied to femininity. Social expectations may therefore prevent many men from practicing other forms of masculinity. The question to be addressed now is which masculinity (or femininity) we perform and when [17].

A literature review examining masculinity and the cancer experience revealed that the majority focused on male only cancers such as prostate cancer [8, $18-21]$. Only one study 
was found that examined the impact of gender in a 'shared' cancer [22]. It demonstrated a difference in spousal support between men and women with CRC, but it also reported diversity among men and women [22]. Examining the impact of gender on the experience of a shared cancer provides an opportunity to compare the male and female experience. It is clear from the literature that there are gaps in studies of men with 'shared' cancers, for example CRC.

The aim of the study was to compare male and female experience of a shared cancer. This paper reports the findings of the participants experience after chemotherapy (the extended stage of survivorship). 


\section{Methods}

A longitudinal qualitative study comparing the experience of men and women with CRC was conducted. Participants were interviewed on four occasions over 18 months; after surgery, on completion of chemotherapy and six and twelve months after chemotherapy. This paper reports the findings from the third and fourth interview.

\section{Sample}

Men and women aged $>18$ years, English speaking, with a diagnosis of CRC attending a regional Cancer Centre formed the sampling frame. The non-probability sampling method of purposive sampling was used, hence a range of patients were selected. Factors considered were gender, age, treatment, and the presence of a stoma. Recruitment continued until no new themes were emerging from the interviews and data saturation had been reached.

\section{Procedure}

Ethical approval was obtained from the Office of Research Ethics Committees in Northern Ireland (ORECNI). Participants were identified during their first oncology appointment. If there was an expression of interest, the potential participants were approached by the researcher and written informed consent was sought. Process consent was used in the study. Each interview was conducted at the participants' venue of choice, at a mutually convenient time.

Interviewees were asked to tell their story from when they first suspected there was a problem. This provided the opportunity for participants to express opinions and describe their unique experience. Issues raised by the participant were explored in detail using a semistructured interview technique. The interview schedule was developed and updated as preliminary analysis revealed emergent themes.

During the first and second interviews, participants were invited to describe their experience of being diagnosed with CRC, undergoing surgery and chemotherapy. The third and fourth interviews (the focus of this paper) explored the participants' experience since completion of treatment. The change in coping strategies over time was also explored.

All but three interviews were conducted in the participants' home; the remainder took place in the individuals' workplace. The participants were interviewed alone or with their partner in 
accordance with their own preference. Interviews lasted approximately 1 hour, were audiotaped and transcribed verbatim by support staff.

Following transcription, the interviewer reviewed the transcript. Other members of the research team reviewed a selection of the transcripts and hence regular discussion occurred on the emerging themes.

\section{Analysis}

Interview tapes were transcribed and analyzed according to Miles and Huberman's [23] techniques of labeling, coding, categorizing and theme development. Data collection and analysis were undertaken concurrently. Recurrent themes were subjected to scrutiny in subsequent interviews until the process reached saturation and the theme could not be developed further. NVIVO was utilized to aid data management. Each participant was assigned an identification number (PIN). This number was used to code each interview, in combination with an $\mathrm{F}$ or $\mathrm{M}$ to denote gender. 


\section{Results}

Recruitment commenced in November 2006 and ended in June 2007. Fifty-six individuals were identified as eligible, 38 agreed to participate (24 men; 14 women). Thirty-two completed a second interview. Twenty four were interviewed at time point 3 (15 men; 9 women). Sixteen participants completed the final interview (10 men; 6 women). The researcher decided not to interview six participants as data saturation had been achieved with these individuals. Participant characteristics are presented in Table 1. The ratio of male to female respondents at each interview remained similar to that at baseline: approximately 2 males to 1 female. Participants received various combinations of cancer treatment, the most common being surgery followed by adjuvant chemotherapy (see Table 2). This paper reports on the participants' experience after treatment (interview 3 and 4).

Three themes emerged from the interviews: new normal, living with uncertainty and support needs. The participants described living with ongoing physical symptoms. This is summarized as their 'new normal'. Upon receiving a cancer diagnosis, many individuals reported a continual feeling of anxiety that their cancer may recur. They were now 'living with uncertainty'. On completion of treatment, a number of participants identified a need for further social support and described a number of unmet 'support needs'.

\section{New normal}

Following treatment many male and female narratives indicated that they were experiencing persistent side effects such as tiredness, watering eyes and/or problems with bowel functioning. This was seen as something they lived with, their 'new normal'. Watering eyes was highlighted as a problem by some male respondents. Their narratives revealed a concern that they were being viewed as emotional, which was not what they considered to be a 'masculine practice', reflective of the stereotypical view that men chose not to cope through emotional expression [16]. One man described his embarrassment in public especially when at a funeral, an emotional situation.

'sometimes the tears can be running and it can be embarrassing. Going to a funeral and people would be thinking you were getting emotional.' 007M 
Over time the participants attempted to reintegrate into 'normal' life. Immediately after chemotherapy many participants described a sense of 'limbo'; they were no longer a cancer patient, but did not feel normal due to persistent side effects:

'Since it stopped the fatigue was worse for a while and perhaps still is affecting me...... can get integrated again with an ordinary routine and I'm not completely out of things like a patient.....halfway between two worlds...' $028 \mathrm{M}$

The female respondents indicated that they were living with side effects, but they were accepting of this. One female with a stoma bag emphasized that she was able to work, exercise and travel. She found the Internet a great source to allow her to live her life as she wanted.

'I was lucky and able to get on the Internet. There are so many things you can get from underwear, gadgets to make life easier......and swimwear ......To me it's just an everyday thing and I don't fuss.' 008F

Similarly a female who did not receive a stoma, but was still experiencing altered bowel habits, did not define them as a problem.

'I go a lot oftener. You would maybe go once a day; I would go four times a day.'

Interviewer: And do you find that restrictive?

'No, no, I just know every toilet in the town. It's all part and parcel.' 040F

Some male respondents emphasised that they were not experiencing any problems. One male narrative indicated that he was living his life as he had prior to his diagnosis.

'Just getting back to normal. I went back to work full again full time......I just do my usual thing.......' $030 \mathrm{M}$

This man was in his twenties. A diagnosis of cancer at a young age can be challenging as it disputes the assumption of youth and health [15]. It has been stated that older men may view illness as part of the aging process and therefore accept the loss of masculinity more readily [24].

Many men, who did admit to experiencing symptoms such as tiredness, seemed to play down their experience. When they acknowledged the 'odd day' of tiredness they attributed this to work or age not to their 'physical stamina' being affected by the illness.

'Fully back to normal...... Well a wee bit of tiredness, but I would say it's my age.' 018M 
'I'm tired because I am tired.......there has been the odd day at work where I've felt knackered but I think that's more to do with the work...... as opposed to.......not having the physical stamina because of the illness.' $001 \mathrm{M}$

This stoic stance often presented by men is consistent with the concept of hegemonic masculinity which portrays men as reluctant to show their vulnerability publicly. However, as the interviews progressed their narratives frequently revealed that they had altered their life (similar to the female respondents) to accommodate their stoma bag or bowel habits. In contrast most of the females were comfortable admitting they were having problems and were able to live with them. This was illustrated by one man, who presented himself as accepting of his illness and having no problems with his altered bowel habits.

'No I don't think about that end of it much. Obviously because it's major surgery...... it's a major change to your body so there are the side effects which you just learn to adapt to and live with, etc, etc.'004M

In contrast, another male spoke openly of the impact of his stoma bag. He described how he reduced his social activities and did not like to plan ahead.

'I feel......if we set aside the colostomy I feel as well now as before the operation. Well it's just managing it......You need to keep looking after it. You have good times and bad times......' $027 \mathrm{M}$

This man did not seem to perceive the same challenges to his masculinity. He was comfortable with admitting he was still having problems managing his stoma bag. This was an elderly, independent, single man. It could be the case that independent living meant that the gender roles normally present in relationships were not evident in this case.

Both male and female participants reported reducing their social activities. Similar to the aforementioned male, one female described how she lacked confidence to travel longer distances:

'I go out, but I don't go very far. I would be scared to go very far you know, with this (stoma bag) in case anything happens'

\section{Living with uncertainty}

It is well documented that uncertainty is linked to surviving cancer [25]. The degree to which this uncertainty impacted on the study participants varied from unconcern to total pre- 
occupation. It would appear the experience could be placed on a continuum, not a binary divide [26]. Only female narratives indicated a preoccupation towards the uncertainty, while evidence of unconcern towards cancer recurrence was only noted in the male narratives. An overlap was noted between the sexes, both men and women reported a moderate response to the uncertainty.

Many male and female accounts indicated that they were living with the uncertainty that their cancer may recur. One female narrative showed how the uncertainty was something that was always with her, but she tried not to become pre-occupied with it.

'now it is always in the back of your mind, there is no doubt about it, but I don't dwell on it.' $008 \mathrm{~F}$

These individuals appeared to have a determination to not let the uncertainty have an influence on their lives. One man rationalised this by emphasising the precarious nature of life in general.

'I thought sometimes yes, my life is under threat because if it came back. But if I dwell on it I can't get on with the rest of my life for whatever length of time is left. You know, I could get run over by a bus' $001 \mathrm{M}$

In contrast, some men presented themselves as having no concerns about their cancer returning. One man, who had also emphasised that he was not having persistent bowel problems, detailed that he was not concerned about the risk of recurrence.

'Well I don't worry......I'm not the worrying type. You know the old song que sera sera.' $004 \mathrm{M}$

This man was a high achieving businessman. Prior to his diagnosis he has been involved in local politics. On diagnosis, he was no longer able to perform this role. Through his narrative he was portraying himself as strong and unconcerned. In doing so he seemed to be reconstructing his position of power.

Evidence of contradiction in the narratives of some men indicates that this may be a front, their attempt at enacting their masculine beliefs. For example, at the beginning of his interview one man describes his anxiety at having to attend for a scan sooner than expected and the implications of that. 
'Well I don't know whether to be...you know...that it's so quick that there is something there or not that didn't show up on the scan.' $(045 \mathrm{M})$

However, later in his narrative he goes on to say:

'As I say......it's there and there is nothing you can do about it......there is no sense in worrying because there is no alot you can do about it.' $045 \mathrm{M}$

This quote in isolation would indicate that this man is not worried about his cancer, yet his narrative would indicate otherwise.

Some females appeared preoccupied at the possibility of recurrence. One female worried that any pain or illness was a sign that her cancer had come back. This was understandable however, as she had already experienced a recurrence at an earlier date.

'I had a terrible bout of gastroenteritis which drained the life out of me and I thought oh God this is back again.' 051F

Another woman described herself as a time bomb, signifying that she believed it was only a matter of time before the bomb went off and her cancer returned.

'All I say is I still keep thinking I'm a time bomb because there are many people who have this cancer thing and they are not even with us now......' $006 \mathrm{~F}$

This lady was a widow who lived alone with little social support. She did not need to have chemotherapy and thus was discharged after surgery. This may have increased her anxiety.

\section{Support needs}

Following chemotherapy, most women appeared to want support while most men did not seem to have the same desire for ongoing support. There were however exceptions to this trend.

After chemotherapy, many participants described persistent physical and psychological difficulties. A number of female narratives revealed that to cope with these difficulties they needed further support. One female described this as a feeling of abandonment.

'whenever all the treatment is over......there is that feeling that you are being abandoned...' $019 \mathrm{~F}$ 
Similarly another female participant stated that a visit from a specialist nurse would prove valuable.

'Yes there does need to be somebody there to catch you......at the end of the chemo and your visits to the hospital because........everybody has gone and left you.' 051F

An account from one male respondent demonstrated that similar to a number of the females, he too missed the support from the hospital.

'it sounds strange but you start looking forward to your trips there (the cancer centre)......it's like another family that you have got outside.' 001M

This was an atypical response, as the majority of male respondents did not appear to have this attitude, their narratives indicated that they did not miss attending for chemotherapy and did not appear to have the same desire for ongoing support or support groups. For example:

Interviewer: 'some people find that when they are not going back to hospital, it's quite difficult to cope......'

'I was glad to not have to go' 007M

Interest in support groups increased at this stage for many participants. One female who was attending a support group found it useful, but stressed this was because all attendees were well.

'We have a support group. They are fine. Everybody is on the road to recovery. There is nobody having treatment or anything at the moment. $051 \mathrm{~F}$

Similarly one female did not attend a support group for this reason; she was feeling apprehensive that a negative story would bring back her anxiety.

I didn't go to any support groups..... I suppose they would have been one thing that I would have been very apprehensive about going because I didn't want to get any negative stories' $008 \mathrm{~F}$

These narratives suggest that some females may not access support groups. This challenges the stereotypical view that females cope through expressing their emotions. Previous literature has also shown that the 'last thing' some females with breast cancer wanted to do was talk about cancer [16]. 
One man who attended a support group stressed in his narrative that he was attending to help others, he was keen to emphasise that he did not need any support.

'I actually go out to them more out of respect and support for the girl that runs it, the stoma sister...... How much I get out of it, I'm not kind of sure' $001 \mathrm{M}$

This demonstrated how a man may change how he enacts masculinity in different social contexts. As a 'patient' in the hospital setting he was accepting of support, however in the more 'public' domain, that is support groups, his attendance was not to help himself, but to help others. In public he felt he had to adopt a more dominant, superior masculine identity $[8,13]$. 


\section{Discussion}

The purpose of this paper was to compare the male and female experience on completion of treatment for CRC. Many men and women reacted similarly, however there was some variation evident between and within sexes. The main difference was with regards to the long term physical side effects, many women admitted to still experiencing side effects, and developed strategies to manage these symptoms hence they did not have a great impact on their lives. In contrast many men engaged in practices that aligned with their gender identity and view of masculinity. They indicated that they had no problems and downplayed the significance of the side effects and possibly did not make attempts to incorporate the symptoms into their daily lives. It must be noted that some men and women were still experiencing an impact. Although the majority of respondents had adapted physically, many were still experiencing a psychological impact of fear of cancer recurrence. How the individuals reacted to this uncertainty could be placed on a spectrum from no concern, through some concern with minimal impact to total preoccupation (see Figure 1). Gender may have an influence on the extreme reactions as only men reported having no concerns and only women experienced total preoccupation.

By the final interview, many individuals (both men and women) appeared to have adjusted to the physical side effects and were no longer defining them as 'problems'. A small number of individuals did report a reduction in social activities, which is similar to work by Rozmovits and Ziebland [27] who reported that some individuals experience a long term negative impact on the ability to socialize. By the fourth interview both males and females reported a fear of cancer recurrence. This finding corroborates previous research; fear of cancer recurrence is often stated as one of the greatest concerns of individuals with CRC [28-32]. This fear of recurrence has been shown to persist for many years following diagnosis [33].

A number of females experienced distress on the removal of the support provided by the healthcare system, whereas many men did not report the same need for long term support. A desire for long term support has been noted in previous studies of CRC [34,35] but they did not report any gender difference. Keller and Henrich [36] suggested that men with CRC rely on their wives support in contrast to females who are unaffected by their husbands support. It could be the case that the male participants in the current study relied mostly on their wives for support and therefore on completion of chemotherapy, their support mechanism remained unchanged. 
Previous research has demonstrated that females with CRC have often been shown to be more emotionally affected than men [37-40]. Foley and colleagues [41] concluded that men more often indicated that the CRC had minimal impact on their lives. This study supports this by demonstrating how gender affects adjustment to CRC, and how gender practice differs from person to person and from context to context on an individual level. Individuals with CRC engage in a range of gender practices, which as alluded to earlier, has been described as 'doing' gender [42]. Many female participants appeared more affected by the physical side effects. They admitted to still having problems with their bowels, but they tried to not let it limit their activities. In contrast, a number of men did not describe the same long term impact. Traditionally women are responsible for juggling multiple roles (mother, partner) and it has been proposed that their sense of identity is greatly affected by a cancer diagnosis and therefore they may experience greater disruption than their male counterparts. The impact may not be as obvious in men as they do not have the same roles to fulfill in the family [16,37]. In contrast many men believe they must cope and adapt quickly [10]. This may lead them to have a shorter transition process [22]. Another argument is that women are more comfortable than men about discussing their emotional distress [37]. It is plausible therefore that both men and women are suffering from the same distress, but the male participants were not willing to share that experience for fear of portraying themselves as less of a man. Women may have a higher awareness of their distress and may be more honest in their responses than men [40].

The study participants did not indicate a strong desire to attend formal support groups. Female participants worried about attending support groups in case another attendee suffered a relapse. This corroborates previous literature which has found that CRC patients are skeptical about dealing with other sick people, although the influence of gender was not examined by the authors [34]. Another study has stated that gender was not related to level of interest in support groups [43].

\section{Limitations}

The sample may not be representative of the views of all individuals with CRC attending the Cancer Centre. Due to the nature of the study, many potential participants may not have felt comfortable discussing their experience. The participants were Caucasians and English speaking, therefore the results cannot be generalized to individuals from other cultures. 
Most of the respondents were in their sixties and occupied traditional gender roles. A study of younger participants with more varied gender roles might produce different findings. To address this issue future research should examine the impact of age on gender roles and the experience of CRC.

In some cases the spouse was present during the interview, usually the female spouse of the male patient. Furthermore, all interviews (except one) were conducted by a female researcher. This may have enhanced the male patients' needs to enact their masculinity. Research interviews provide a context for the performance of gender, and may not reflect 'actual' gender practices [44].

There were successes and challenges in using a longitudinal qualitative design. Over time a rapport developed between the interviewer and the respondent which may have led to the respondent providing a deeper insight into their experience. In some cases, the interviews led to repetition of data, as the participants' experience had not changed since the previous interview. This led to withdrawals as they felt they had nothing more to add. As the interviewer followed the participants over an 18-month period she developed a relationship with the respondent, and found it difficult to not become emotionally involved.

\section{Recommendations}

Rather than a sudden removal of support at the end of chemotherapy, a gradual decrease in support may prove more beneficial. Particular attention should be paid to female participants at this stage. Support from a specialist nurse could prove valuable. Health care professionals (HCPs) should be aware that recovery from the physical and psychological effects of CRC does not occur in parallel and those individuals with CRC may experience persistent anxiety about cancer recurrence. HCPs should be aware that men may be suffering from physical symptoms or psychological distress although they may be reluctant to discuss them. If these men are disinclined to show their emotions in public it is possible that they are not providing a full insight into their experience in a research interview. Future research should use more creative methods to probe deeper into their needs, perhaps through case studies or diaries. The different ways that men and women react to their illness may be influenced by gender expectations which HCPs may hold about masculine and feminine behaviours. HCPs should be aware that not all men (or women) conform to the social stereotypes of masculinity (or femininity) and that the concept of gender is not as straight 
forward as the traditional view of masculinity and femininity being a stable set of attributes that distinguish men from women. There are variation within sexes and individual variation dependent on context. 


\section{References}

1) National Cancer Institute. A snapshot of colorectal cancer. 2008 Available from: http://www.cancer.gov [Accessed $16^{\text {th }}$ July 2009]

2) Cancer Research UK. Bowel (colorectal cancer): UK bowel cancer statistics. 2009 Available from: http://info.cancerresearchuk.org/cancerstats/types/bowel [Accessed 16th July 2009]

3) Coleman MP, Rachet B, Woods LM, Mitry E, Riga M, Cooper N, Quinn MJ, Brenner $\mathrm{H}$, Estève J. Trends and socio-economic inequalities in cancer survival in England and Wales up to 2001. Br J Cancer 2004;90:1367-1373.

4) Gatta G, Ciccolallo L, Faivre J, Bouvier A-M, Berrino F, Gerard JP. Late outcomes of colorectal cancer treatment: a FES-EUROCARE study. J Cancer Surviv 2007;1:247254.

5) Mullan F. Seasons of survival: reflections of a physician with cancer. New Eng J Med 1985;313:270-273.

6) Beckjord EB, Arora NK, McLaughlin W, Oakley-Girvan I, Hamilton AS, Hesse BW. Health-related information needs in a large and diverse sample of adult cancer survivors: implications for cancer care. J Cancer Surviv 2008;2:179-189.

7) Ganz PA. A teachable moment for oncologists: cancer survivors, 10 million strong and growing! J Clin Oncol 2005;23:5458-5460.

8) Wall D, Kristjanson L. Men, culture and hegemonic masculinity: understanding the experience of prostate cancer. Nurs Inq 2005; 12: 87 - 97.

9) Gerson J, Peiss K. Boundaries, negotiation, consciousness: reconceptualizing gender relations Social Problems 1985;32: 317 - 331.

10) Courtenay W. Constructions of masculinity and their influence on men's well-being: a theory of gender and health. Soc Sci Health 2000;50: $1385-1401$.

11) Moynihan C. Theories of masculinity. BMJ 1998;317:1072 - 1074.

12) Emslie $C$, Hunt $K$, MacIntyre S. Problematizing gender, work and health: the relationship between gender, occupational grade, working conditions and minor morbidity in full-time bank employees. Soc Sci Med 1999;48: 33 - 48.

13) Connell RW, Messerschmidt JW. Hegemonic masculinity: rethinking the concept. Gender and Society 2005;19: 829 - 859.

14) Connell RW. Masculinities. Berkeley: University of California Press. 1995

15) Hilton S, Emslie C, Hunt K, Chapple A, Ziebland S. Disclosing a cancer diagnosis to friends and family: a gendered analysis of young men's and women's experiences. Qual Health Res 2009;19: 744 - 754. 
16) Emslie C, Whyte F, Campbell A, Mutrie N, Lee L, Ritchie D, Kearney N. 'I wouldn't be interested in just sitting round a table talking about cancer': explaining the experience of women with breast cancer in a group exercise trial. Health Educ Res 2007;22: 827-838.

17) Paechter C. Masculinities and feminities as communities of practice. Women's Stud Int Forum 2003;26: 69 - 72.

18) Broom A. Prostate cancer and masculinity in Australian Society: a case of stolen identity. Int J Men's Health 2004;3: 73 - 91.

19) Oliffe J. Embodied masculinity and androgen deprivation therapy. Sociology of Health and Illness 2006;28: 410 - 432.

20) Arrington M.I. Prostate cancer and the social construction of masculine sexual identity. Int J Men's Health 2008;7: 299 - 306.

21) Kelly D. Changed men: the embodied impact of prostate cancer. Qual Health Res 2009;19: $151-163$.

22) Emslie C, Browne S, MacLeod U, Rozmovits L, Mitchell E, Ziebland S. 'Getting through' not 'going under': a qualitative study of gender and spousal support after a diagnosis of colorectal cancer. Soc Sci Med 2009;68: 1169-1175.

23) Miles MB, Huberman M. Qualitative Data Analysis: an expanded sources book. Sage Publication, Thousand Oaks, California, 1994.

24) O'Brien R, Hunt K, Hart G. Men's accounts of masculinity and help seeking: "It's caveman stuff, but that is to a certain extent how guys still operate." Soc Sci Med 2005;61: $503-516$.

25) Dow K.H. Enduring seasons in survival. Oncol Nurs Forum 1990;17:511-516.

26) Annandale E, Riska E. New connections: towards a gender inclusive approach to women's and men's health. Current Sociology 2009;57: 123 - 133.

27) Rozmovits L, Ziebland S. Expressions of loss of adulthood in the narratives of people with colorectal cancer. Qual Health Res 2004;14: 187 - 203.

28) Northouse LL, Schafer J, Tipton J, Metivier L. The concerns of patients and spouses after the diagnosis of colon cancer: a qualitative analysis. $J$ Wound Ostomy Continence Nurs 1999;26:8-17.

29) Sahay TB, Gray RE, Fitch M. A qualitative study of patient perspectives on colorectal cancer. Cancer Pract 2000;8:38-44.

30) Dunn J, Lynch B, Rinaldis M, Pakenham K, McPherson L, Owen N, Leggett B, Newman B, Aitken J. Dimensions of quality of life and psycho-social variables most salient to colorectal cancer patients. Psycho-oncol 2006;15:20-30. 
31) Houldin AD, Lewis FM. Salvaging their normal lives: a qualitative study of patients with recently diagnosed advanced colorectal cancer. Oncol Nurs Forum 2006;33:719725.

32) Simpson MF, Whyte F. Patients' experiences of completing treatment for colorectal cancer in a Scottish District General Hospital. Eur J Cancer Care 2006;15:172-182.

33) Foster C, Wright D, Hill H, Hopkinson J, Roffe L. Psychosocial implications of living five years or more following a cancer diagnosis: a systematic review of the research evidence. Eur J Cancer Care 2009;18: 223 - 247.

34) Ross L, Johansen C. Psychosocial home visits in cancer treatment. Cancer Nurs 2002;25:350-357.

35) Rozmovits L, Rose P, Ziebland S. In the absence of evidence who chooses: a qualitative study of patients' needs after treatment for colorectal cancer. Journal of Health Services Research Policy 2004;9: 159-164.

36) Keller M, Henrich G. Illness-related distress: does it mean the same for men and women? Acta Oncologica 1999;38:747-755.

37) Northouse LL, Mood D, Templin T, Mellon S, George T. Couples patterns of adjustment to colon cancer. Social Sci Med 2000;50:271-284.

38) Tuinstra J, Hagedoorn M, Van Sonderen E, Ranchor AV, Van den Bos GAM, Nijboer C, Sanderman R. Psychological distress in couples dealing with colorectal cancer: gender and role differences and intracouple correspondence. $\mathrm{Br} J$ Health Psychol 2004;9:465-478.

39) Hagedoorn M, Sanderman R, Bolks HN, Tuinstra J, Coyne JC. Distress in couples with cancer: a meta-analysis and critical review of role and gender effects. Psychol Bull 2008;134:1-30.

40) Ernstmann N, Neumann M, Ommen O, Golushka M, Wirtz M, Voltz R, Hallek M, Pfaff H. Determinants and implications of cancer patients' psycho-social needs. Support Care Cancer 2009 [Epub Ahead of Print].

41) Foley KL, Farmer DF, Petronis VM, Smith RG, McGraw S, Smith K, Carver CS, Avis N. A qualitative exploration of the experience among long-term survivors: comparisons by cancer type, ethnicity, gender, and age. Psycho-oncol 2006;15:248258.

42) West C, Zimmerman D. Doing gender. Gender and Society 1991;1:125-151

43) Bui LL, Last L, Bradley H, Law C, Maier B-A, Smith AJ. Interest and participation in support group programs among patients with colorectal cancer. Cancer Nurs 2002;25: $150-157$. 
44) O'Brien R, Hart G, Hunt K. 'Standing out from the herd': Men renegotiating masculinity in relation to their experience of illness. Inter J Men's Health 2007; 6:178-200 
Table 1 Participant demographics

\begin{tabular}{|c|c|}
\hline & $\mathbf{N}$ \\
\hline Total number of participants & 38 \\
\hline \multicolumn{2}{|l|}{ Age } \\
\hline Mean (SD) & $60(12.15)$ \\
\hline \multicolumn{2}{|l|}{ Sex } \\
\hline Male & 24 \\
\hline Female & 14 \\
\hline \multicolumn{2}{|l|}{ Marital Status } \\
\hline Married & 32 \\
\hline Single & 4 \\
\hline Divorced & 1 \\
\hline Widowed & 1 \\
\hline \multicolumn{2}{|l|}{ Employment status (at time of diagnosis) } \\
\hline Working & 18 \\
\hline Not working & 20 \\
\hline
\end{tabular}

Table 2 Treatment received

\begin{tabular}{|r|c|}
\hline Total number of participants & N \\
\hline Anti-cancer treatment received & 38 \\
\hline Surgery & 5 \\
\hline Surgery + stoma & 2 \\
\hline Surgery + chemotherapy & 18 \\
\hline Purgery + stoma + chemotherapy & 7 \\
\hline Pre-op radiotherapy + surgery + stoma + & 1 \\
chemotherapy & 2 \\
\hline
\end{tabular}


Figure 1

Reaction to uncertainty

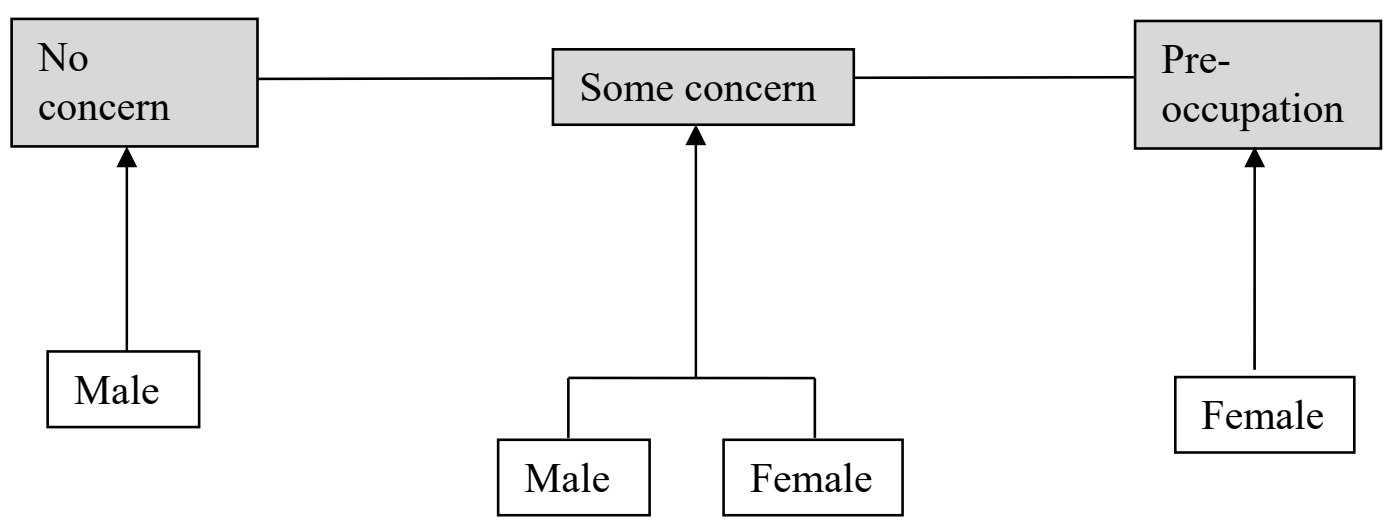

